\title{
EVALUATING AND MANAGING POTENTIAL GROUNDWATER POLLUTION FROM LEAKING USTs AT A COASTAL CITY IN SAUDI ARABIA
}

\author{
M.S. AL-SUWAIYAN \\ Civil Engineering Department, King Fahd University of Petroleum \& Minerals, Dhahran, Saudi Arabia.
}

\begin{abstract}
Leaking underground fuel storage tanks (USTs) are the main source of petroleum hydrocarbon contamination of soil and groundwater. The distribution and flow of the leaked hydrocarbon is influenced by capillary and gravity forces. Depending on the leaked volume and the soil properties, the hydrocarbon could exist as a residual phase completely held in the soil above the water table or as both free phase product and residual. Various components of gasoline will affect the groundwater quality and each will spread according to its own characteristics. The pollution processes are studied through the development of a combination of two models: a compositional and a potential flow model. The former was developed using the mass balance principle and is capable of using the organic compound and the subsurface properties to predict the concentration of the various components of benzene, toluene and xylene (BTX) mixture in a leachate from a site contaminated by a residual mixture. Potential flow theory was utilized to model the advective transport of contaminants towards municipal wells. Capture zones were defined and travel times for different municipal wells were estimated for a sample study area at a coastal city in eastern Saudi Arabia. Modeling and field survey indicated the high potential for groundwater pollution and concluding that more effort should be directed to promote leak prevention through management strategies that include developing proper design regulations and installation requirements like monitoring wells for new and existing service stations.
\end{abstract}

Keywords: groundwater management, leaking USTs, modeling groundwater pollution, water resources.

\section{INTRODUCTION}

Most countries in the Arabian Peninsula and north and central Africa are situated in the water scarce region according to MENA [1]. Saudi Arabia in particular has essentially negligible surface water which makes its groundwater resources highly important that have to be utilized in an efficient way in order to sustain its development. This important source is not only being mined but also it is susceptible to pollution. The value of this resource can be reduced drastically if its quality deteriorates.

Leakage from underground fuel storage tanks (USTs) is a main source of soil and groundwater contamination. USTs, which are essential parts of all gas stations, represent potential sources of subsurface contamination. Fuel leaks can take place through the tank itself due to corrosion, which is typical for older USTs, or through the associated piping systems, which may take place at both new and old stations. The distribution and flow of the hydrocarbon, after a leak, is influenced by both capillary and gravity forces. The hydrocarbon can exist in four phases:

1. A residual phase held by capillary and adsorptive forces

2. A vapor phase

3. A free phase product

4. Dissolved in the groundwater

The groundwater quality will be affected not only by the dissolved hydrocarbon phase but also by all other phases. Contaminants from all phases will slowly dissolve in the flowing groundwater as well as recharge water forming a contamination plume, which will spread in the direction of regional 
groundwater gradient. The growth and movement of the contamination plume will be influenced by type of contaminant, groundwater velocity and direction, aquifer heterogeneity and subsurface properties including distribution coefficients and microorganisms.

Contaminant transport in the subsurface environment is not well understood by the public. Many people believe that this environment will degrade many contaminants given enough time. The main fact that contributes to this misconception is the hidden nature of the subsurface. It is well known that contaminants that enter the subsurface will eventually make it to the groundwater aquifer, which could be a drinking water source [2].

During the last three decades, Saudi Arabia, the largest producer and exporter of oil, has undergone huge and rapid urbanization and agricultural development which cannot be sustained without the availability of enough water. According to the Ministry of Planning [3], the population jumped from 7 million in 1974 to close to 23 million in 2004. Water is not only vital for human life but enough water must be available if we are to sustain the development of natural resources and quality of life. Saudi Arabia has an arid environment with practically no surface water and the main sources of water are groundwater and desalination plants [4]. The country produces and consumes 316 barrels of gasoline daily [3], which passes through USTs below service stations scattered around municipalities. The potential for groundwater pollution due to accidental leaks is high given the lack of proper guidelines and regulations during design, installation and monitoring of USTs. This paper presents a modeling study aiming to assess the potential contamination of groundwater by leaking USTs, its possible consequences and expected time frame before municipal water supply is directly affected. This study also reviews that current regulations are practices related to USTs and at the end possible ways to mange this problem and to reduce such risk are presented.

\section{FATE OF CONTAMINANTS AFTER A LEAK}

Assuming static equilibrium in a homogeneous porous media, the distribution of the three fluids: air, hydrocarbon and water will be influenced by the capillary pressure values and the relationship between the capillary pressure and saturation for the system [5]. If we assume that the water saturation is controlled by the value of the capillary pressure for the water (wetting fluid)-oil (non-wetting fluid), and the total liquid saturation is controlled by the value of the capillary pressure for the oil (wetting fluid)-air (non-wetting fluid), it would be possible to plot the water and the total liquid saturation along a vertical section in the contaminated subsurface.

Using the fact that the capillary pressure between water and hydrocarbon is zero at their interface in a fully screened well and since the capillary pressure between hydrocarbon and air is zero at the surface of the free product in that well, fluids' saturation along the vertical can be generated.

Farr et al. [6] as well as Lenhard and Parker [7] showed that the vertical distribution of an hydrocarbon after a spill is expected to be influenced by the spill volume, soil properties like displacement head, distribution index and value of residual saturation. These properties reflect the grain-size distribution in the aquifer material which varies significantly from one location to another. Hydrocarbon properties also influence its distribution including density, surface tension, viscosity, solubility and volatility. In general, a hydrocarbon can exist in either of four classes. It can be held by capillary and adsorptive forces in the unsaturated/saturated zone as residual or immobile phase which approximately remain in its place but slowly dissolving part of its mass with any water flow. It can also exist as a vapor phase in the unsaturated zone or as free phase near the water table and in monitoring wells. Finally, it can exist as a dissolved phase in groundwater at relatively very low concentrations but note that most of these products are very harmful to humans even at trace levels.

Field investigation at this stage could be used for assessing the extent of contamination and knowing the area distribution of the released contaminants. It may involve sampling of aquifer material, 
construction of wells screened in hydrocarbon zone and wells screened below the water table, which can provide information such as thickness of hydrocarbon in wells, concentration of dissolved contaminants as well as approximate water table elevation. These are the primary data that must be used to evaluate nature and extent of groundwater pollution. Soil samples collected during the field investigation can be taken to the laboratory to get their grain-size distribution which may be in turn used in models such as the one presented by Mishra et al. [8] to generate a first approximation for the hydraulic properties of the subsurface. Hydrocarbon distribution in layered soils was studied by Al-Suwaiyan et al. [9]. A review for estimating spill volume is presented by Saleem et al. [10].

It is well established that monitoring wells are not reliable for spill detection and quantification since in many field cases, leaks are accidentally discovered by detecting free product in utility manholes not by finding free product monitoring wells.

\section{STUDY AREA}

The city of Alkhobar is located in the eastern province of Saudi Arabia and sets on the eastern shore of the Arabian Gulf. This area has undergone huge development and population growth along with the oil industry. According to the official data, it has a population of 166,000. The central part of the city $(10 \mathrm{~km} \times 10 \mathrm{~km})$ was selected to evaluate the potential groundwater pollution as well as developing strategies for controlling possible pollution. The conditions at Alkhobar are similar to other cities of the same size around the developing world and the general results of the study are expected to apply to some degree on other similar cities. This city in particular and Saudi Arabia at large lack renewable water sources such as rivers, lakes or dependable precipitation and rely mostly on mining groundwater. In addition, sea water desalination gained attention and support from the Saudi government to the degree that today Saudi Arabia became the top user of sea water desalination with 30 plants that produce about 3 million cubic meters daily [3]. According to the water authority, the water supply to the central part of the city comes from desalination (45\%) and groundwater through 16 municipal wells (55\%). The locations of these wells and their average flow rates are given in Fig. 1 and Table 1 consecutively. The area also contains 16 major gas stations that are considered potential sources for groundwater pollution. The locations of these potential sources are also shown in Fig. 1.

Table 1: Water supply to central Alkhobar.

\begin{tabular}{lc}
\hline Well \# & Average, $\mathrm{Q}\left(\mathrm{m}^{3} /\right.$ day $)$ \\
\hline 1 & 3637 \\
2 & 3087 \\
3 & 14,549 \\
4 & 6379 \\
5 & 5320 \\
6 & 4689 \\
7 & 76 \\
8 & 2162 \\
9 & 362 \\
10 & 8626 \\
Total groundwater & 52,800 \\
Desalination source & 45,200 \\
\hline
\end{tabular}




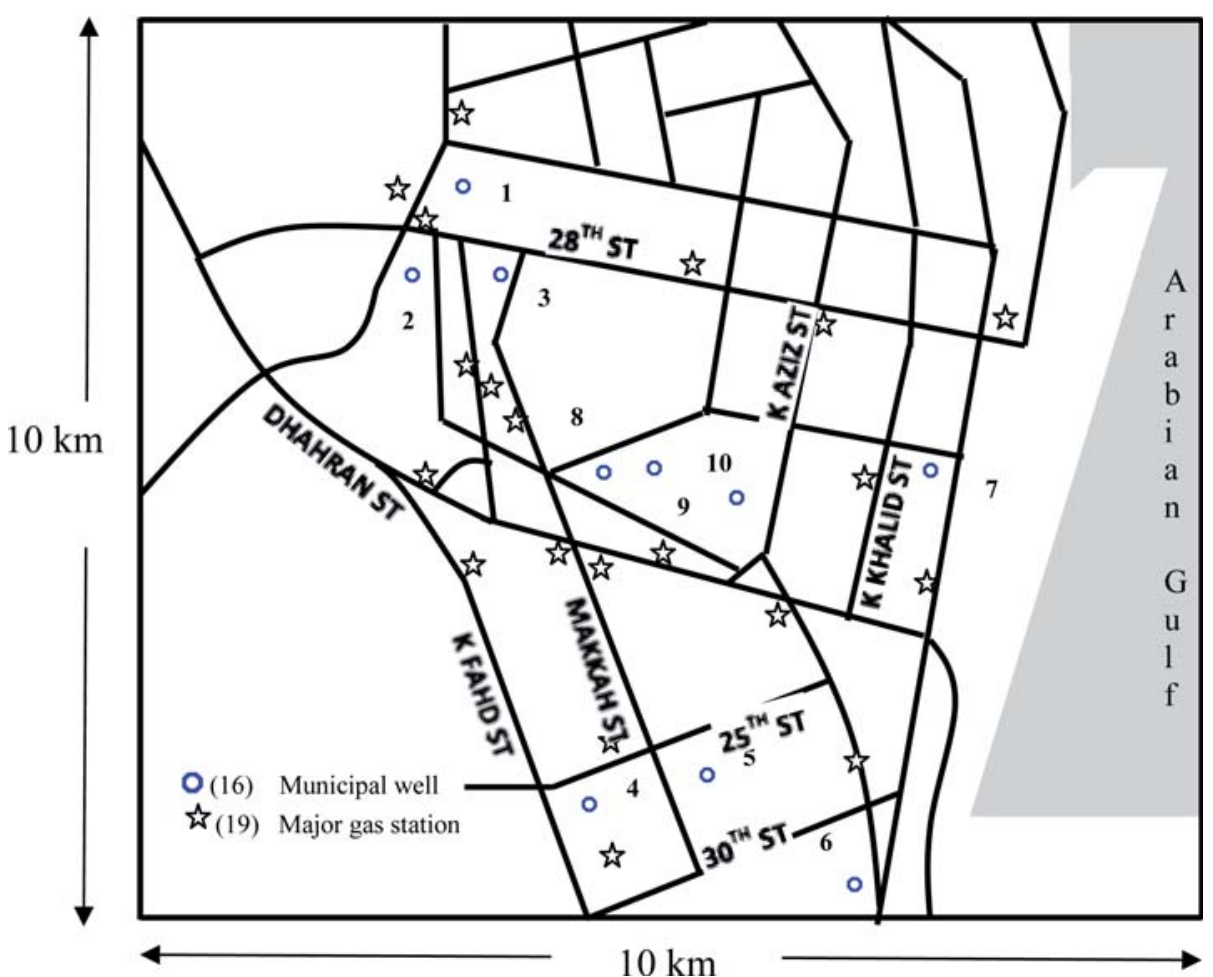

Figure 1: Central Alkhobar map showing municipal wells and major gas stations.

\subsection{Hydrogeology of study site}

Based on the results of hydrogeological studies by Italconsult [11], BRGM [12] and GDC [13], three main aquifers separated by semi-confining beds were identified in the eastern Saudi Arabia. The aquifer system with intervening aquitards with ascending order is: the Umm Er Radhuma aquifer, the Rus aquitard with Midra and Saila Shales and Alveolina Limestones, the Al-Khobar aquifer, the Orange Marl aquitard, and the Alat aquifer and the Neogene aquitard. The upper two aquifers are sometimes called Dammam aquifer.

The hydraulic properties of these aquifers are affected by the lithology, fissures and solution cavities that are common in limestone formation. The confining and semi-confining layers are expected not to be continuous; in fact, direct contact between the various units is possible. As a result of the nature of the subsurface, big leaks will reach the water table quickly due to preferential flow in fissures and cavities proven to be present at the local subsurface.

\subsection{Hydraulic properties of Dammam aquifer}

From the mentioned reports [11-13] as well as published papers [14, 15], the average transmissivity of the Al-Khobar aquifer is around $2.9 \times 10^{-5} \mathrm{~m}^{2} / \mathrm{s}$ whereas the transmissivity of the Alat aquifer varies from $3.1 \times 10^{-4} \mathrm{~m}^{2} / \mathrm{s}$ to $2.3 \times 10^{-3} \mathrm{~m}^{2} / \mathrm{s}$. The storativity value ranges from $1.5 \times 10^{-4}$ to $2.6 \times$ $10^{-4}$ indicating the confining behavior of the aquifer. The Alat aquifer behaves semi-confined to 
unconfined near the erosional surfaces at and around the Dammam Dome. A reasonable value which will be adopted in this study for the transmissivity is the value reported in [14] which is $350 \mathrm{~m}^{2} /$ day. The groundwater gradient results in almost easterly flow towards the Arabian Gulf with a gradient of about 0.001 .

\section{SUBSURFACE NEAR PETROLEUM PROCESSING FACILITIES}

The subsurface near petroleum processing facilities or aging service station most likely will contain many organic compounds originally existing in oil. Among these compounds are benzene, toluene and xylene (BTX). BTX are common organic pollutants associated with accidental leaks of common fuels. Their presence in the subsurface will result eventually in groundwater contamination which can create a hazard affecting human health. The health effects associated with long term expose to these products according to EPA [16] include chromosome aberrations, cancer, liver and kidney damage, damage to central nervous system, nervous disorders including spasms, tremors, impairment of speck, hearing, vision, memory, coordination. National Primary Drinking Water Regulations [16] gives maximum contaminant levels (MCLs) of $5 \mathrm{ppb}, 1 \mathrm{ppm}$ and $10 \mathrm{ppm}$ for benzene, toluene and xylene, respectively. Depending on the hydrocarbon spill volume, groundwater contamination could be mainly as a result of the free product pool that forms just on top of the water as is the case for big leaks. In this case, direct dissolution or partitioning of the organic compounds between the water and the free hydrocarbon is governed by Raoult's Law. For smaller leaks, groundwater contamination is due to leaching of the hydrocarbon components and their movement in the vadose zone towards the water table. Figures 2 and 3 show the two cases of groundwater contamination. To assess the degree of possible groundwater pollution from an accidental spill, the characteristics of the leachate from the contaminated zone, mainly pollutant concentrations has to be studied which can be done by developing a compositional model. Once the leached contaminants reach groundwater they will be carried along with the flowing water contaminating the aquifer and possibly taking them to municipal wells resulting in direct threat to humans. The time of arrival into municipal wells will be quantified through the use of potential flow modeling.

\section{MODELING LEACHATE FROM RESIDUAL CONTAMINATION}

A hypothetical limited leak could take place below a fuel processing facility resulting in a zone contaminated with residual hydrocarbon. In this case, the product will be under negative pressure and will be stationary. Such case is idealized as shown in Fig. 3. The shaded area near ground surface represents an idealized zone polluted by residual amounts of BTX. As water infiltrates due to precipitation, irrigation or process activities, it will leach these contaminants slowly forming a continuous source of contamination into the underlying unconfined aquifer. In this section, the compositional model presented by Al-Suwaiyan [17] is presented after upgrading to include a natural degradation process which is represented by a first order reaction. The developed model is then used to study the process of contaminant leaching from the zone of residual contamination.

\subsection{Model development}

As was indicated by Al-Suwaiyan [17], the leaked organic contaminants in the unsaturated zone of residual contamination will partition between four possible phases, namely water, air, soil and free hydrocarbon. For each component, the concentration in water is related to the bulk concentration through:

$$
m_{i}=B_{w_{i}} C_{w_{i}}
$$




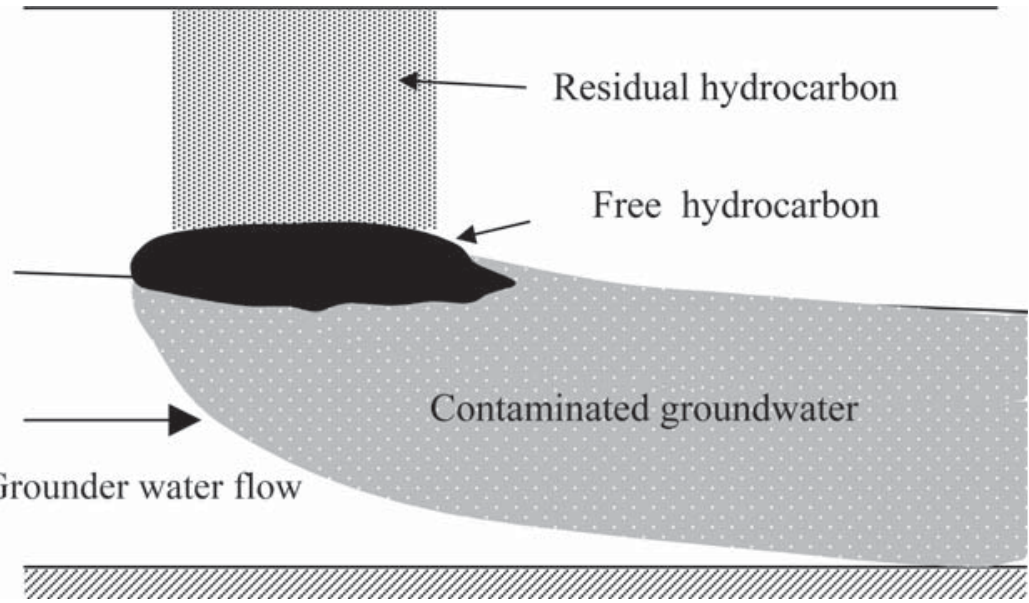

Figure 2: Schematic view for contaminated subsurface due to free hydrocarbon.

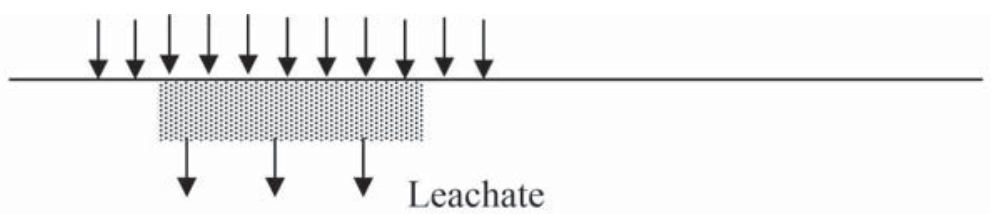

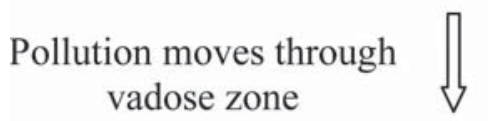
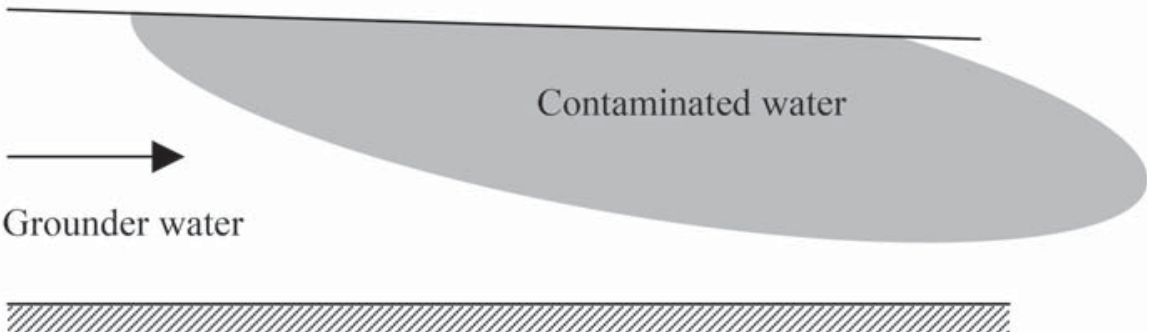

Figure 3: Schematic view for contaminated subsurface due to residual hydrocarbon.

where $m_{\mathrm{i}}=$ bulk concentration of compound $i, C_{W i}=$ concentration of compound $i$ in water and $B_{W i}=$ the bulk water partitioning coefficient for compound $i$. It will be influenced by component volatility, adsorption properties as well as the distribution of compound in the free hydrocarbon.

Charbeneau [18] gives the following equation for the bulk partitioning coefficient:

$$
B_{w}=\theta_{w}+\theta_{a} K_{H}+\theta_{o h} K_{o h}+\rho_{b} K_{d}
$$


where $\theta_{w}=$ volumetric water content, $\theta_{a}=$ volumetric air content, $\theta_{\text {oh }}=$ volumetric content of non-aqueous phase liquid, $\rho_{b}=$ bulk density, $K_{H}=$ Henry's constant, $K_{d}=$ distribution constant and $K_{o h}=$ NAPL water partitioning coefficient.

To develop the characteristics of the leachate from the contaminated zone, the mass balance principle is used for each component in the organic mixture. In the upgraded model, the mass can be lost due to leaching water as well as due to natural degradation.

Using Fig. 3, the total mass present for compound $i$ is given by:

$$
M_{i}=A L_{o} B_{w_{i}} C_{w_{i}}
$$

where $M_{i}=$ total mass of compound $i, A=$ area of contaminated zone and $L_{0}=$ depth of contaminated zone.

Natural degradation due to microorganisms' activity or radioactive decay could be represented by a first order reaction (with half-time $T_{1 / 2}$ ) given by:

$$
\frac{d}{d t}\left(B_{W i} C_{W i}\right)=-\frac{0.693}{T_{1 / 2}} B_{W i} C_{W i}
$$

Neglecting volatility and assuming mass is lost only with leaching water and degradation, the mass balance equation becomes:

$$
\frac{d M_{i}}{d t}=\frac{d}{d t}\left[\begin{array}{lll}
A & L_{o} & B_{w_{i}} C_{w_{i}}
\end{array}\right]=-A\left(q+\frac{0.693}{T_{1 / 2}} L_{0} B_{W i}\right) C_{W i}
$$

where $q$ is the rate of water percolation.

Due to the variability in $B_{w i}$, iterative numerical procedure is used to solve this problem. Initially, the composition of the contaminated zone is developed through field investigation and assessment. Equation (5) gives the rate of mass change inside the polluted zone which can be assumed constant for small time increment $\Delta t$. The remaining mass at the next time level is calculated for each constituent and the resulting distribution is used to adjust sensitive parameters in eqn (2) like $\theta_{a}, \theta_{o h}, K_{o h}$ before re-evaluating the bulk partitioning coefficients for the next time interval. This iterative process is repeated using a reasonable time step size to obtain each constituent's remaining mass and the concentration at various times. A step size of one day was used throughout this analysis.

\subsection{Leaching model results}

The developed compositional model was used to study and predict the characteristics of the leachate leaving a contaminated zone. This leachate will eventually reach and be a source of pollution to the underlying aquifer. The flux rate of polluting mass as well as the cumulative pollution was also modeled. In addition, the influence of environmental degradation is examined through the comparison of the model predictions with resulted previously presented in [17] in which degradation was neglected. The model was applied to the hypothetical case shown in Fig. 3, using the same values given in [17] for the parameters involved for meaningful comparison. These values are: a porosity of 0.45 , a water flow rate of $1 \mathrm{~cm} /$ day, and an average moisture content of 0.225 , a residual hydrocarbon content of 0.0675 and contaminated depth of $10 \mathrm{~cm}$. The contaminating mixture consisted of equal volumes of BTX. For examining natural degradation within the contaminated zone, the half-life in soil for the three compounds were taken as the average values reported by Howard et al. [19]. These values are 370, 18 and 190 days for benzene, toluene and xylene, respectively. 
The developed model is used below to study the composition of the leachate, its variation with respect to time as well as to examine the influence of natural degradation on BTX concentrations and on the mass flux into the aquifer. The temporal variation in concentrations of the three compounds for two cases, considering and excluding degradation, are shown simultaneously in Fig. 4. When degradation is neglected, as was indicated by Al-Suwaiyan [17], benzene acts as the dominant pollutant affecting groundwater at early times, however, its concentration decreases at a relatively sharp rate. Toluene becomes the main pollutant where it will be depleted at a high rate for some time leading its depletion and making xylene the more significant pollutant. This is due to their close affinity to the soil matrix, the variation in solubility in water. The leachate composition when degradation is included in the model will be dominated by benzene for the first 10 months after which xylene takes over until it is totally depleted. The figure also indicates clearly the effect of degradation particularly in toluene, which has a relatively short half-life. Toluene practically disappears in the leachate after about 4 months. Smaller effect for degradation on benzene is clear from Fig. 4 which is attributed to the relatively low degradation rate (i.e. high half-life). Xylene, on the other hand, is influenced by degradation but much smaller than toluene. For both cases, it is clear that the leachate characteristics vary with time and concentrations are much higher than the MCLs which is expected to have a drastic effect on the underlying aquifer.

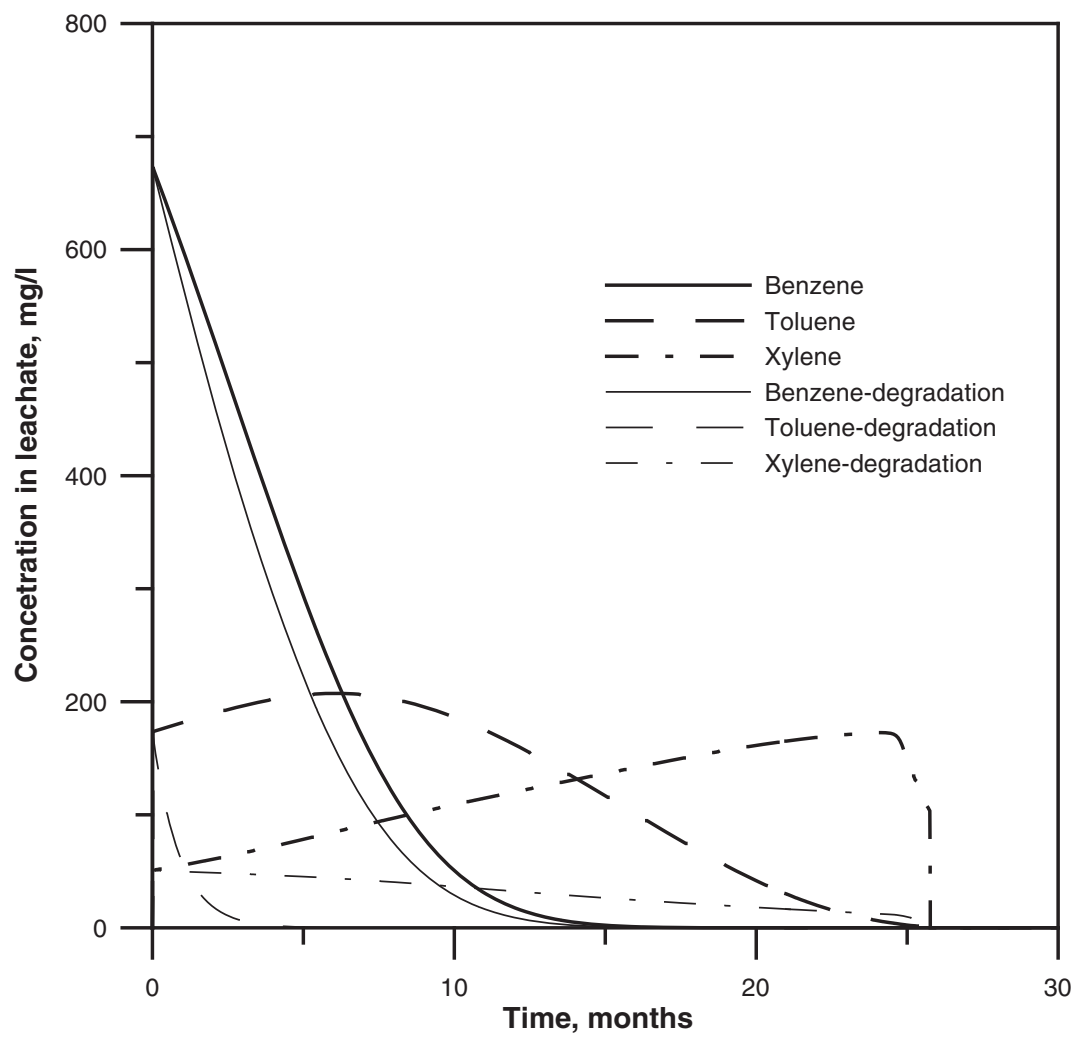

Figure 4: Aqueous concentration for different compounds in leachate. 


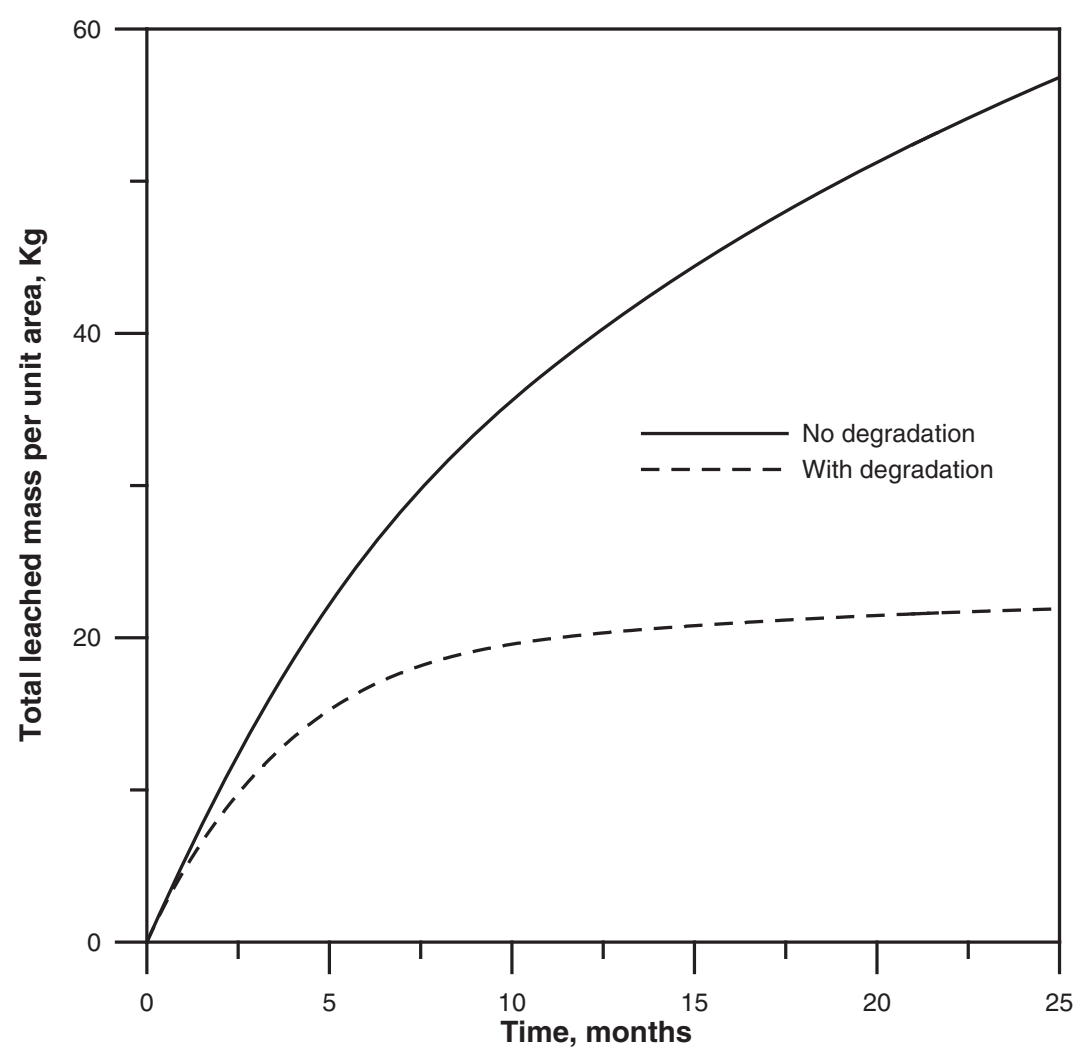

Figure 5: Total mass entering aquifer.

The total mass released from the contaminated zone per unit area which eventually will reach the water table for the two cases (neglecting and considering degradation effect) is shown in Fig. 5. For both cases, his total polluting mass is an increasing function. When degradation is considered, the total mass reaches a constant value of about $22 \mathrm{~kg} / \mathrm{m}^{2}$ of polluted area in about 9 months. The composition of this mass is expected to be dominated by benzene at early times and by xylene later.

Temporal variation of the rate of mass flux per unit area is shown in Fig. 6 which clearly shows the influence of natural degradation within the polluted zone. It results in much sharper decrease in mass flux into the aquifer. In both cases, the rate starts high continuously decreases but with tailing. Figure 6 actually gives the pollution source which is clearly variable in terms of mass flow rate as well as composition or concentration of contaminants. The contaminants concentration in groundwater will be obviously affected by this variable source resulting in a pollution plume with variable characteristics making the remediation process more difficult.

\section{CAPTURE ZONE ANALYSIS}

Making use of the potential flow theory, flow in homogeneous aquifers can be relatively easy to model for situations involving uniform flow and producing or recharge wells. The streamline can be developed and thus capture zones for each well can be defined and questions related to potential pollution or lack of may be answered. 


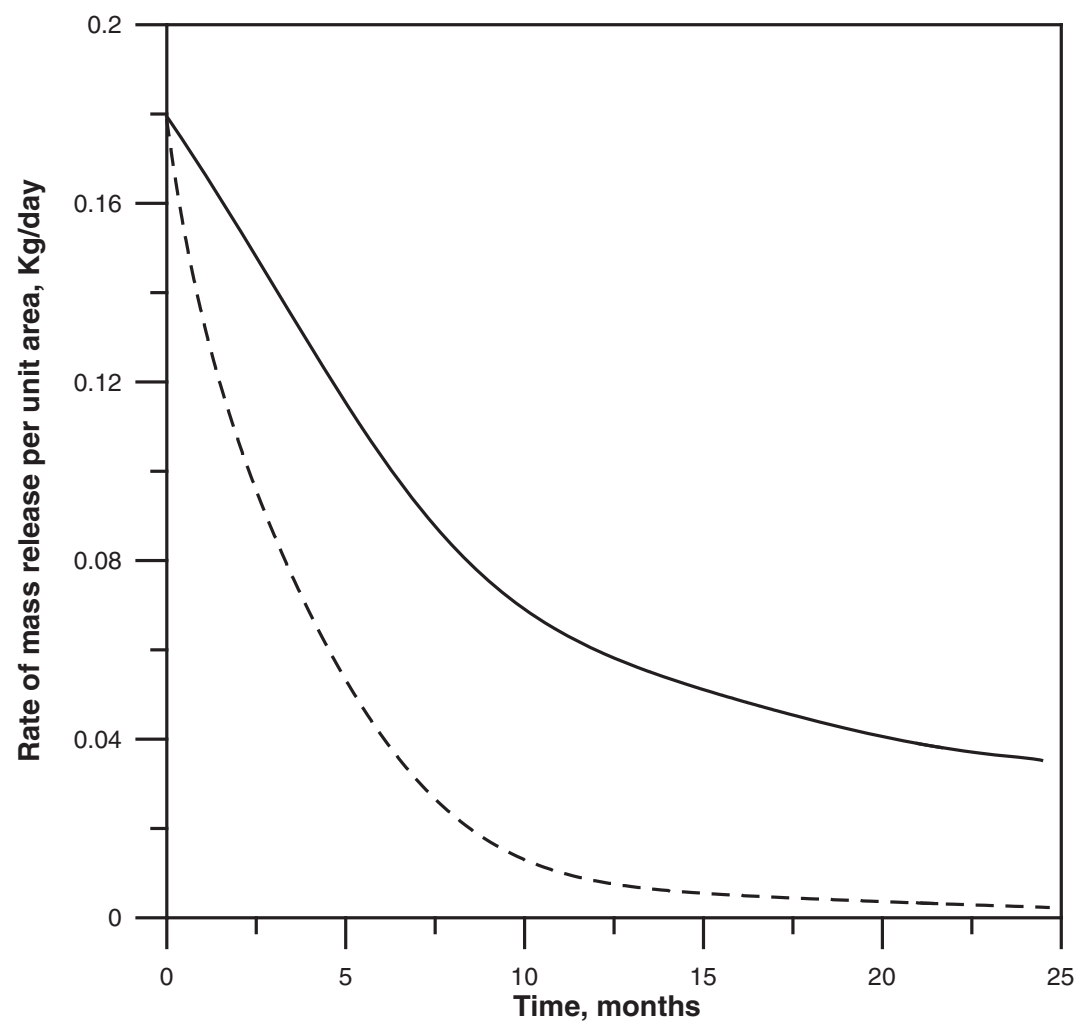

Figure 6: Rate of contamination source.

6.1 Stream function for producing wells in a uniform field

The stream function for the case of a pumping well located at the coordinates origin in a uniform field can be modified from McWhorter and Sunada [20] written as:

$$
\psi=-Q_{x} y+\frac{Q_{w}}{2 \pi} \tan ^{-1}\left(\frac{y}{x}\right)=C
$$

where $\psi=$ stream function, $Q_{x}=$ uniform aquifer flux ( $\mathrm{m}^{2} /$ day), $Q_{w}=$ producing well pumping rate $\left(\mathrm{m}^{3} /\right.$ day), $x, y=$ coordinates whose origin is at the well and $\mathrm{x}$-axis in the direction of regional flow and $C=$ arbitrary constant.

The equation for the well's capture zone is obtained by setting the arbitrary constant to zero yielding:

$$
x=\frac{y}{\tan \left(\frac{2 \pi Q_{x} y}{Q_{w}}\right)}
$$

Capture zones for the individual wells will be presented and discussed later in this paper. 
Using superposition, for more than one well the stream function will be:

$$
\psi=-Q_{x} y+\Sigma \frac{Q_{i}}{2 \pi} \tan ^{-1}\left(\frac{y-y_{i}}{x-x_{i}}\right)=C
$$

where $Q_{i}=$ pumping rate for well $i\left(\mathrm{~m}^{3} /\right.$ day) and $x_{i}, y_{i}=$ coordinates defining the location of well $i$.

Travel time analysis for a contamination source to reach a municipal well allows us to estimate the range of time that is expected before contamination becomes clear. It is a useful tool for evaluating various alternatives for aquifer management.

Bear and Jacob [21] derived a formula for estimating the travel time from a pollution source to a pumping well. This formula is valid for the case of a single well in an infinite, homogeneous aquifer with regional flow in the $\mathrm{x}$-direction provided that the pollution source is within the well's capture zone. The formula can be written as:

$$
t=\frac{\varphi b Q_{w}}{2 \pi Q_{x}^{2}}\left[\ln \left(\frac{\sin \left(\tan ^{-1}(y / x)\right.}{\sin \left(\tan ^{-1}(y / x)+\frac{2 \pi Q_{x} y}{Q_{w}}\right)}\right)+\frac{2 \pi Q_{x} x}{Q_{w}}\right]
$$

where $\varphi=$ porosity, $b=$ aquifer thickness and $x, y=$ coordinates of source.

Equation (9) may be used as guide for the case of a well field provided that the pollution source lies within the capture zone of a particular well. The reliability of this prediction obviously will increase as the cross-influence between the wells decreases such as the case where big distances separate the wells which is assumed in this analysis.

\section{MODELING STUDY SITE}

As was indicated above, the study area gets $55 \%$ of its water from 16 wells which is shown in Fig. 1 . Field survey also indicated the existence of 19 major gas stations whose locations are also shown in Fig. 1. To assess the potential contamination of the municipal wells from fuel leaks in the gas stations, capture zones for the well field was developed utilizing eqn (8) and the average characteristics of the groundwater aquifer and the average pumping rates given in Table 1. The resulting aggregate capture zone is shown in Fig. 7, which clearly shows that about half of the study area falls in the captures zone of the well field indicating the high potential for groundwater pollution from many gas stations. To simplify the modeling process, the interaction between the wells is assumed insignificant which allows the use of individual well's capture zones for potential pollution assessment and breakthrough time estimation. This assumption is a good approximation for the real situation especially if we are not interested in regions very close to the wells. Figure 8, as an example, gives the predicted capture zone for municipal well 3 and clearly shows that three of the major gas stations lie within the well's capture zone. This means that any accidental leak from one or more of these gas stations will directly contaminate the municipal well. It could take a long time for this contamination to occur at the well but once it is detected it means that huge part of the aquifer is already contaminated and major restoration will be required. As indicated above, similar conclusion was obtained when the aggregate capture zone was examined. If one looks at the individual capture zones for all the wells shown together in Fig. 9, it is realized that most of the western side of the study area lies in the municipal wells' capture zone which means that all gas station on that side represent major 


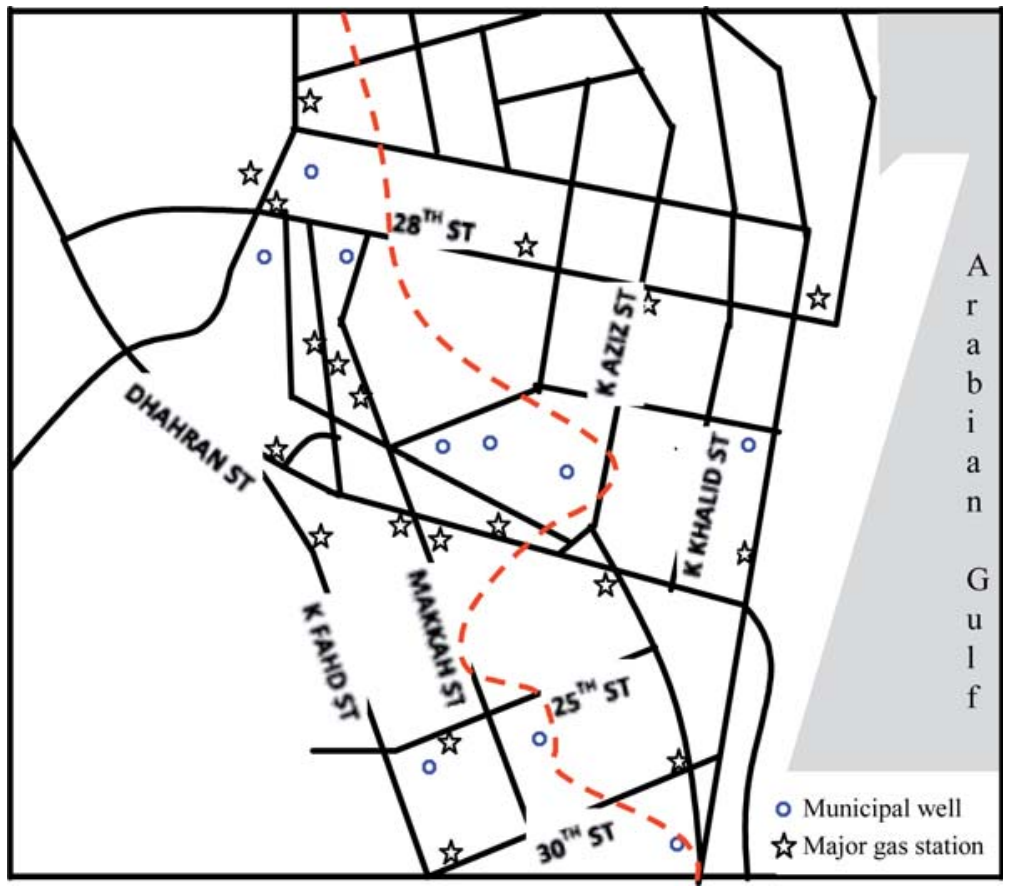

Figure 7: Aggregate capture zone.

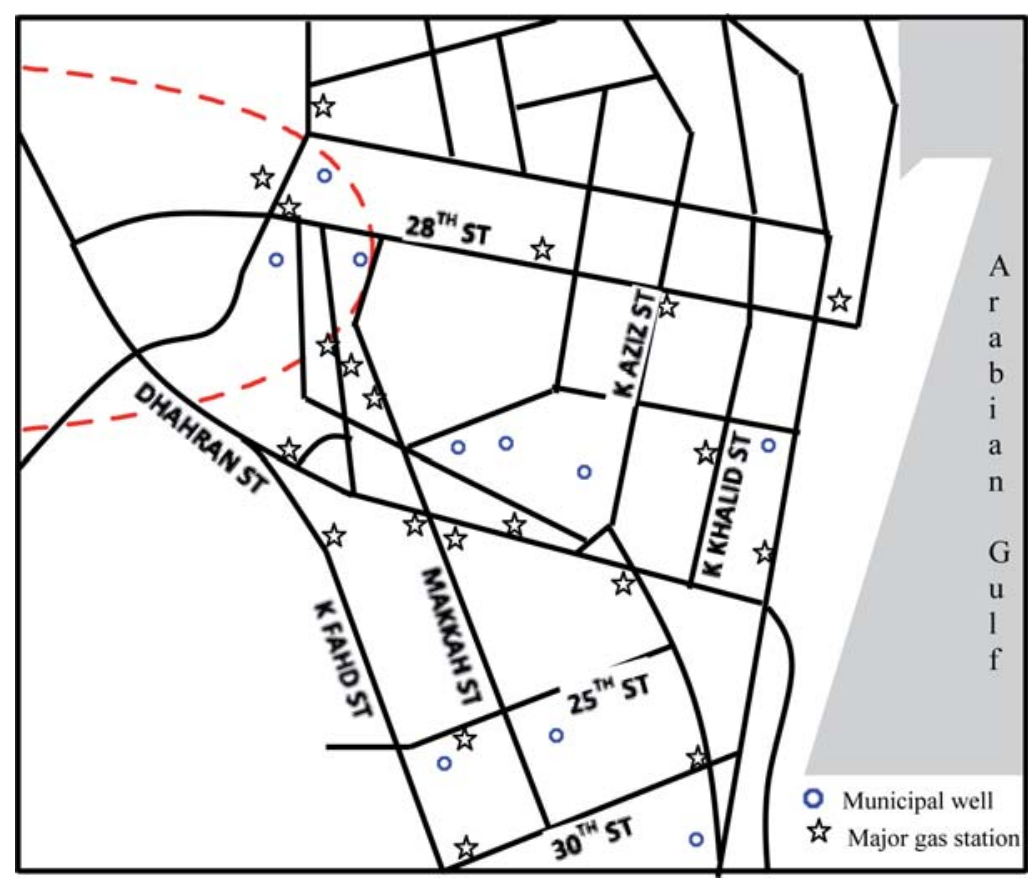

Figure 8: Capture zone for well \# 3. 


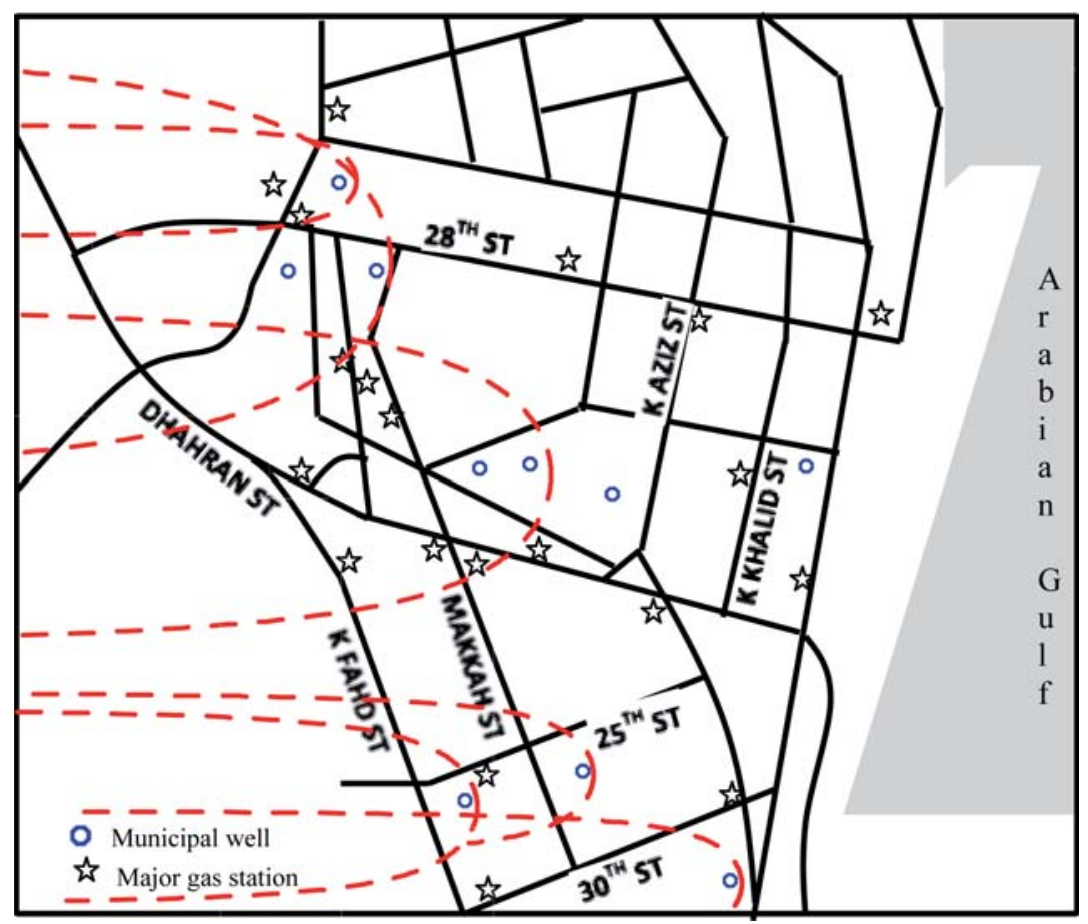

Figure 9: Capture zone for all wells.

pollution potential. Dealing with individual capture zones allows the use of eqn (9) to estimate the expected time span for a contamination below a gas station to reach municipal wells. The results based on this assumption are given in Table 2 for four of the municipal wells. The earliest contamination could appear at municipal well \# 1 if a UST leak takes place below service station \# 3. According to the model, this would take about 1.2 years from the time the leachate reaches groundwater. On the other hand, the travel time from gas station \# 14 to well \# 6 is calculated to be 7.1 years. With the variation and inherited uncertainty, it is clear that proper management is essential to minimize this potential and not to allow any accidental contamination to grow without notice to create major episode which requires expensive and time demanding.

\section{FIELD SURVEY AND LOCAL PRACTICES}

This section presents the results and findings obtained through field visits and review of available documents from licensing agencies related to USTs. This material is naturally divided into two distinct parts, namely local practices and performance of service stations. The findings came after site visits that included governmental agencies related to licensing USTs which are: civil defense, municipality, tank manufacturers as well as many new and old service stations in the greater Dammam-Khobar-Dhahran area.

\subsection{Local practices related to service stations}

From visits and investigations, it was found that the needed permits for constructing a service station have to come from two different governmental agencies, namely civil defense department and 
Table 2: Expected travel times from source to well.

\begin{tabular}{lcc}
\hline Service station \# & Municipal well \# & T, days (years) \\
\hline 2 & 1 & $603(1.7)$ \\
3 & 1 & $438(1.2)$ \\
4 & 8 & $2368(6.5)$ \\
5 & 8 & $1733(4.7)$ \\
6 & 8 & $1152(3.2)$ \\
7 & 8 & $2041(5.6)$ \\
8 & 8 & $2143(5.9)$ \\
9 & 8 & $1127(3.1)$ \\
10 & 8 & $1275(3.5)$ \\
13 & 5 & $766(2.1)$ \\
14 & 6 & $2589(7.1)$ \\
\hline
\end{tabular}

municipalities. Meetings with civil defense officials in Dammam as well as engineers from urban development were conducted and the process of getting the approval was discussed. The main concern was related to the USTs in service stations. In particular, the main concern was to know governmental regulations related to USTs and who is in charge of enforcing these regulations.

Some of the regulations related to USTs appear as part of a manual called 'Laws Regulating Service stations: Fuel, Lubrication and Car Washing' which was issued by the Ministry of Municipal and Rural Affairs, 2002. This manual contained different regulations related to various aspects of service stations. Part of this manual was related to USTs which includes the following regulations.

\subsubsection{Regulations related to underground fuel tanks}

1. Fuel tanks should be placed at least $1 \mathrm{~m}$ below ground surface unless an approval is obtained from civil defense.

2. Fuel tanks should be within the boundaries of the facility in a well ventilated location over which no structures are allowed. For multi-tanks, the distance between the outside walls must be at least $1 \mathrm{~m}$.

3. Tanks should be protected from passing and parked vehicles by covering the ground above by reinforced concrete slab having a minimum thickness of $15 \mathrm{~cm}$ covering the crew above them and extending at least $30 \mathrm{~cm}$ in all directions. Tanks should be in a safe place and locked using special devices and supplied by proper manhole for maintenance and inspection.

4. The following technical and environmental precautions should be done to prevent leaks:

a. For new facility, the tank should be installed underground in a reinforced concrete room well isolated with enough space around the body of the tank to allow accessibility and easy inspection from all direction as well as taking care of any fuel leaks that could take place. The tanks should be tightened to the bottom (base) and allowing spacing at least $1 \mathrm{~m}$ between the tank and walls. The room should be supplied with an opening and a ladder for inspection of tanks.

b. For tanks covered by sand and gravel, the facility owner is required to use modern electronic means connected to the control room for measuring fuel quantity in the tank and detection of any leak that may exist and dealing with it. 
c. For non-steel tank, proper installation and insulation and maintenance should be done according to the manufacturers' guidelines.

\subsubsection{Actual practice}

An official application is filed to the concerned department in the municipality which reviews it and indicates a classification for the facility and then the owner is asked to submit appropriate drawing and design which is reviewed then approved before issuing an official approval to start construction. When construction is complete, civil defense inspects and makes sure that safety requirements are met, however, from our discussion with civil defense, we were told that USTs are not part of their inspection. After that a formal permit is issued which can be used to get fuel and start operation.

Both governmental agencies (civil defense and urban development) indicated clearly that nobody formally enforces these regulations and this matter is left to the owner of the gas station along with the tank manufacturer.

In a recent study by Al-Suwaiyan et al. [22], a survey and site visits were conducted in order to evaluate the potential risk of groundwater pollution due to USTs. Important information related the storage tanks, routine monitoring, maintenance, preventive maintenance as well as laws and regulation existence as well as enforcement were collected and reviewed. The results revealed that a significant number of service stations had old tanks made using reinforce concrete and that they never received maintenance which is a must given the aggressive subsurface environment. The study also showed the lack of protection from corrosion and only about $20 \%$ had cathodic protection. Any monitoring was absent in close to $60 \%$ of the service stations surveyed. Similarly, emergency response practices were lacking. Given the limited geographical area for this study, it still can be expected to roughly represent the actual conditions in many developing countries. This lack in all aspects, leads one to conclude that the risk for contaminating the underlying aquifers is high.

\section{SUMMARY AND RECOMMENDATIONS}

A field investigative study coupled with a two-phase modeling study was conducted to evaluate potential groundwater pollution and possible management strategies on an area located in central Alkhobar city in eastern Saudi Arabia. The first phase of the modeling study resulted in the development of a compositional model capable of handling natural degradation. The developed model was used to study the leachate characteristics and transport of pollutants in the unsaturated zone. In the second phase, capture zones were determined for several municipal wells and times for contamination to reach the wells were estimated in order to have some idea about the nature and extent of this environmental problem. Modeling results and field visits and previous studies reveal the high potential for groundwater pollution as a result of fuel leakage from USTs and the need for implementation of proper steps that would result in reducing such potential. The following recommendations are expected to reduce such potential:

a. Creating an agency or department in charge of implementation and inspection of the various aspects of USTs including installation certification, monitoring and maintenance. This comes as a result of the lack in that aspect revealed by the process of reviewing current practices related to USTs.

b. Development of zoning for new service stations with the wellhead protection for the municipal wells in mind. This should take into consideration aquifer properties, direction of groundwater gradient and current and potential locations for municipal wells. As an example based on the modeling study, minimum number of gas stations should be allowed in the western side of the city since most of that area lies within the municipal wells capture zone. 
c. Service stations should have an active role in protecting groundwater aquifers through regular monitoring of the groundwater quality just down gradient of the facility. This can be accomplished by requiring the construction of at least one monitoring well from which samples are collected and analyzed at regular intervals. This action will allow early detection of contamination plumes. Such well can also play an important role in protecting the municipal wells since it can be used to create a hydraulic barrier and be a part of a pump and treat system.

\section{ACKNOWLEDGEMENT}

The support provided by the Civil Engineering Department at King Fahd University of Petroleum and Minerals is highly appreciated.

\section{REFERENCES}

[1] MENA, The World Bank - Middle East \& North Africa (MENA) Water Resources Management, Electronic Report, 2000.

[2] National Research Council, Innovations in Ground Water and Soil Cleanup, National Academy Press: Washington, DC, 1997.

[3] Ministry of Economics \& Planning, Eight Development Plan 1425-1430, Ministry of Economics \& Planning Press: Riyadh, Saudi Arabia, 2004.

[4] Van der Leeden, F., Troise, F.L. \& Todd, D.K. eds., The Water Encyclopedia, 2nd edn, Lewis Publishers: Chelsea, MI, 1990. doi:http://dx.doi.org/10.2136/sssaj1980.03615995004400050002x

[5] Van Genuchten, M.Th., A closed-form equation for predicting the hydraulic conductivity of unsaturated soils. Soil Science Society of America Journal, 44, pp. 892-898, 1980.

[6] Farr, A.M., Houghtalen, R.J. \& McWhorter, D.B., Volume estimation of light nonaqueous phase liquids in porous media. Ground Water, 28(1), pp. 48-56, 1990. doi:http://dx.doi. org/10.1111/j.1745-6584.1990.tb02228.x

[7] Lenhard, R.J. \& Parker, J.C., Estimation of free hydrocarbon volume from fluid levels in monitoring wells. Ground Water, 28(1), pp. 57-67, 1990. doi:http://dx.doi. org/10.1111/j.1745-6584.1990.tb02229.x

[8] Mishra, S., Parker, J.C. \& Singhal, N., Estimation of soil hydraulic properties and their uncertainty from particle size distribution data. Journal of Hydrology, 108, pp. 1-18, 1989. doi:http://dx.doi.org/10.1016/0022-1694(89)90275-8

[9] Al-Suwaiyan, M.S., Bashir, K., Aiban, S.A. \& Ishaq, A.M., Analytical model to quantify crude oil spills in sandy layered aquifers. Journal of Environmental Engineering, ASCE, 128(4), pp. 320-326, 2002. doi:http://dx.doi.org/10.1061/(ASCE)0733-9372(2002)128:4(320)

[10] Saleem, M., Al-Suwaiyan, M., Aiban, S., Ishaq, A.M., Al-Malack, M. \& Hussain, M., Estimation of spilled hydrocarbon volume-the state-of-the-art. Environmental Technology, 25(9), pp. 1077-1090, 2004. doi:http://dx.doi.org/10.1080/09593330.2004.9619401

[11] ITALCONSULT, Water and Agricultural Development Studies for Area IV, Eastern Province, Saudi Arabia, unpublished report to Ministry of Agricultural and Water, Riyadh, Saudi Arabia, 1969.

[12] Bureau De Recherche Geologiques et Mineres (BRGM), Al-Hassa Development Project: Groundwater Resources Study and Management Program, unpublished report to Ministry of Agriculture and Water, Riyadh, Saudi Arabia, 1977. doi:http://dx.doi.org/10.1016/ 0022-1694(65)90065-X

[13] Groundwater Development Consultants (GDC), Umm Er Radhuma Study: Bahrain Assignment, unpublished report to Ministry of Agriculture and Water, GDC: Riyadh, Saudi Arabia, Cambridge, UK, 1980. 
[14] Zubari, W., Khater, A., Al-Noaimi, M. \& Al-Junaid, S., Spatial and temporal trends in groundwater salinity in Bahrain. The Arabian Journal for Science and Engineering, 22(1C), pp. 81-94, 1997.

[15] Abderrahman, W., Elamin, A., Al-Harazin, I. \& Eqnaibi, B., Management of groundwater in urban centers: a case study greater Dammam metropolitan area. The Arabian Journal for Science and Engineering, 32(1C), pp. 51-63, 2007.

[16] United States Environmental Protection Agency (USEPA), The Office of Ground Water \& Drinking Water Web Site, Washington DC, http://www.epa.gov/OGWDW

[17] Al-Suwaiyan, M.S., Controlling groundwater pollution from petroleum products leaks, Environmental Toxicology III. WIT Transactions on Ecology and the Environment, vol. 132, eds. V. Popov \& C.A. Brebbia, WIT Press: Southampton, pp. 91-99, 2010.

[18] Charbeneau, R.J., Groundwater Hydraulics and Pollutant Transport, Prentice Hall: Upper Saddle River, New Jersey, 2000.

[19] Howard, P.H., Boethling, R.S., Jarvis, W.F., Meylan, W.M. \& Michalenko, E.M., Handbook of Environmental Degradation Rates, Lewis Publishers, Inc.: Chelsea, MI, 1991.

[20] McWhorter, D.B. \& Sunada, D.K., Ground-Water Hydrology and Hydraulics, Water Resources Publications: Fort Collins, CO, 1988.

[21] Bear, J. \& Jacob, M., On the movement of water bodies injected into aquifers. Journal of Hydrology, 3, pp. 37-57, 1965.

[22] Al-Suwaiyan, M.S., Ishaq, A.M., Essa, M.H. \& Saleem, M., Assessment of the status of USTs at service stations in eastern Saudi Arabia, Proceedings of the Fourth Saudi Technical Conference, Riyadh, pp. 286-293, 2006. 